\title{
The place of heparins in the treatment of venous thromboembolism
}

\author{
Andrzej Wojtak, Tomasz Zubilewicz \\ Department of Vascular Surgery and Angiology, Medical University of Lublin, Poland
}

\begin{abstract}
Venous thromboembolism, in the form of lower limb deep vein thrombosis and its most dangerous complication that is a pulmonary embolism, is a common disease with an increasing incidence associated with the ageing population. The scheme of VTE treatment underwent changes when a new drug group — directly and selectively acting oral anticoagulants — was introduced. However, the scope of VTE therapy with parenterally administered low-molecular-weight heparins was wide, i.e., they produced vast progress in the disease's treatment in the 1980s.
\end{abstract}

Key words: venous thromboembolism, low-molecular-weight heparin, enoxaparin, deep vein thrombosis, pulmonary embolism

Acta Angiol 2019; 25, I: 35-40

\section{Introduction}

Venous thromboembolism (VTE) is associated with the formation of blood clots inside deep veins, which inhibit or block venous blood flow. It includes deep vein thrombosis (DVT) and/or pulmonary embolism (PE). The most frequent location of DVT are lower limbs; it occurs less frequently in the veins of the pelvis and upper limbs. The stable thrombi formed damage walls of the vein and destroy venous valves, whereas unstable, balloting thrombi may move and be transported to pulmonary vessels with venous blood flow. This results in symptoms of pulmonary embolism, which is the most frequent cause of sudden death of patients treated in hospitals.

Deep vein thrombosis is characterized by limb edema and pain, and skin colour may change to bright red or blue. Distally located DVT may remain asymptomatic and its only proxymal propagation may result in intensified symptoms. Pulmonary embolism frequently begins with dyspnea and thoracic pain and it may result in hypotonia, loss of conscience, or sudden death.

Annually, it is estimated that DVT and PE are developed by 57,000 and 36,000 persons, respectively, in
Poland [I]. The prevalence of DVT is approximately I per I,000 persons [2], whereas the prevalence of $\mathrm{PE}$ is from 3 to 4 per 10,000 persons. DVT is present in $70-80 \%$ of persons with PE, but only I $5 \%$ of PE patients exhibit clinical symptoms of DVT [3]. A history of VTE predisposes a person for its recrudescence. After the cessation of anticoagulant therapy, the disease may relapse in approx. Ten percent of VTE patients within one year from the first event [4], and in $30 \%$ of them, recrudescence occurs within 10 years from the first event [5]. VTE is also associated with considerable mortality, which amounts to approx. $5 \%$ after I year of its existence [6].

DVT risk factors can be classified as provoked or unprovoked, i.e., those, which cannot be fully identified [7]. The first group includes surgical procedures, prolonged immobilization, injuries, obesity, long travels, valvular incompetence, using oral contraceptive agents, or hormone replacement therapy and pregnancy [2, 7].

DVT diagnostics includes a physical examination and recording of clinical history with concomitant use of Wells score [8], additionally a lower limb ultrasonography pressure test or full Doppler test should be performed [9]. One of the tools used for assessing

Address for correspondence: Andrzej Wojtak, Department of Vascular Surgery and Angiology, Medical University of Lublin, Poland, e-mail: aa.wojtak@gmail.com 
the risk of VTE in medical treatment ward is the Padua Score, where a value $\geq 4$ is associated with a high risk of developing the disease $(2.2-11 \%)$ and constitutes an indication for commencement of prophylaxis [10]. In patients subject to surgical procedures, a modified Caprini model for VTE risk assessment can be used [I].

PE diagnostics consists of determining the likelihood of its occurrence using the Wells scale and the YEARS index, as well as determining the D-Dimer concentration in the blood and possible angioCT test of pulmonary arteries. The YEARS score includes three parameters: clinical symptoms of VTE, hemoptysis, and the assumption that PE is the most likely diagnosis [I I].

Prophylactic procedures used in VTE include early ambulation of the patient, administration of an anticoagulant treatment: low-molecular-weight heparin (LMWH), unfractionated heparin (UFH), factor II or Xa inhibitors, and mechanical methods such as compression therapy and intermittent pneumatic compression (IPC). In patients with low or moderate risk of bleeding who are administered with pharmacological prophylaxis, concomitant administration of mechanical methods of prophylaxis is suggested (stockings with graduated compression and/or IPC) whereas in the case of high risk of bleeding - use of graduated compression stockings and/or IPC at least in the initial period, until the risk of bleeding is reduced [12].

VTE treatment guidelines include the possibility of using drugs from various groups: LMWH (fondaparinux) [13], vitamin $\mathrm{K}$ antagonists (VKA) [I3], and oral anticoagulants that are not vitamin $\mathrm{K}$ antagonists (DOAC, NOAC) [14]. Thus, it is very important to maintain the balance between the prevention of VTE recrudescences and the occurrence of bleeding complications in the course of VTE treatment [15]. One of the VKA therapy restrictions is the need for constant INR monitoring to ensure optimum anticoagulation in numerous interactions with other drugs and foods [16]. One of the treatment options used in deep vein thrombosis therapy and pulmonary embolism is sodium enoxaparin administered subcutaneously, two times per day at the dose of $100 \mathrm{IU} / \mathrm{kg}$ of body weight $(\mathrm{I} \mathrm{mg} / \mathrm{kg}$ of body weight) as well as in a single dose, $150 \mathrm{lU} / \mathrm{kg}$ of body weight per day ( $1.5 \mathrm{mg} / \mathrm{kg}$ of body weight). The dosage decision for a given patient should be individualized, based on the experience of the physician and on the assessment of thromboembolic and bleeding risk. This enoxaparin dosage scheme is indicated in patients with a low risk of VTE recrudescence, who do not exhibit complications. Enoxaparin dosage at $100 \mathrm{IU} / \mathrm{kg}$ of body weight ( $\mathrm{I} \mathrm{mg} / \mathrm{kg}$ of body weight) twice per day is applicable for patients with high recrudescence risk with coxal-femoral axis thrombosis, obesity, symptomatic pulmonary embolism, and cancer [I7].
Enoxaparin is one of the most frequently used and, at the same time, clinically studied $\mathrm{LMWH}$, exhibiting high anti-Xa activity, low anti-Ila activity, and antithrombin activity, which is mediated by antithrombin III (ATIII). Moreover, it inhibits other coagulation factors such as VIla and von Willebrand factor (AWF). Inactivation of $X$ a factor may also occur through the action of $\mathrm{LMWH}$ on the vessel endothelium and release of endogenous tissue factor pathway inhibitor (TFPI) [I8].

One of the greatest advantages of LMWH treatment is its predictable, dose-dependent antithrombotic effect. In the majority of cases, it does not require laboratory monitoring. However, in patients with renal impairment, LMWH pharmacokinetics is changed, and thus it is recommendedto reduce their dose with creatinine clearance $<30 \mathrm{~mL} / \mathrm{min}$ and possible monitoring of the anti-Xa activity level in the body. The authors of a meta-analysis conducted in 2006 demonstrated an elevated risk of bleeding with therapeutic doses of enoxaparin ( $8.3 \%$ vs. $2.4 \%$ ), at the same time, pointing out to a reduction of such complications when utilizing empirically determined enoxaparin doses $(0.9 \%$ vs. I.9\%) [19]. In all elderly patients, assessment of kidney function is recommended prior to the commencement of pharmacotherapy [12]. This is of particular importance in patients with diabetes and chronic renal failure, in persons using spironolactones, angiotensin convertase inhibitors because of the high risk of hyperkalemia during long-term LMWH use, particularly at therapeutic doses occurring as a result of post-heparin inhibition of aldosterone secretion by adrenal glands [20].

VTE occurs with high frequency in patients hospitalized due to other indications and it is one of the most common causes for deaths, which could be prevented by applying recommendations of antithrombotic prophylaxis. The risk of its occurrence increases greatly with age and in residents < 40 years of age; it ranges from $25 / 100,000$ to about $300 / 100,000$ per year in residents in the age range of 85-89 years [2I]. In elderly people, the following physiological factors that increase VTE risk occur elevated levels of fibrinogen, factors V, VII, VIII, IX [22], and von Willebrand factor [23]. At the same time, fibrinolytic activity decreases due to increased concentration of the inhibitor of plasminogen activator type I(PAI-I) [24].

Advantages of LMWH in comparison to standard heparin, which have determined their superiority and their gradual replacement of anticoagulant treatment were greater bioavailability, longer half-life resulting in the possibility of their usage I-2 times per day and the ease of dosage adjustment (based on patient's body weight), lack of the need for monitoring, and lower frequency of serious bleeding complications. However, it should be borne in mind that the use of enoxaparin 
in combination with acetylsalicylic acid, NSAID, glucocorticosteroids, clopidogrel, thrombolytic drugs, and other antithrombotic drugs impose on physicians who recommend such treatments the need for careful monitoring of clinical symptoms in patients and periodic determination of blood coagulation parameters [17]. The oral anticoagulants available in Poland (dabigatran, rivaroxaban, and apixaban) do not interact with diet components; however, they are not devoid of interactions with other drugs.

A very important issue concerning $\mathrm{LMWH}$ selection in VTE treatment is the possibility of treatment initiation using LMWH by a family doctor or other general practitioners. Only a suspicion of VTE diagnosis constitutes an indication for administration of heparin and referring such a patient for further, detailed diagnosis. Difficulties in accessing vascular surgery specialists and unavailability of quick and detailed diagnostics such as Doppler ultrasound examination authorizes physicians who are visited by patients with symptoms of edema and pain in lower limbs and/or dyspnea, cough, and pain in the chest to introduce LMWH treatment and its continuation until the diagnosis is confirmed or rejected by physicians specializing in the aforementioned fields.

Pregnant and breastfeeding women constitute special indications for the use of LMWH as the anticoagulant drug for VTE treatment. VTE may occur at any stage of gestation or during puerperium. The risk of VTE is 5-6-fold higher during gestation [25]. It is manifested as $\mathrm{PE}$ and/or deep vein thrombosis and on average it concerns I per 1000 pregnancies [26]. The risk factors of VTE in obstetrics can be divided into two groups: [I] general, not associated with gestation and [2] directly stemming from gestation. This second group includes surgical procedures during gestation or puerperium, superficial vein thrombosis, cesarian birth, polycystic ovary syndrome, prolonged birth, infections during pregnancy, premature placental separation and immobilization associated with a

high-risk pregnancy. The armamentarium of drugs used in VTE prophylaxis includes LMWH, HNF, and oral anticoagulants belonging to the vitamin $\mathrm{K}$ antagonist group. A prophylactic dose of enoxaparin is $40 \mathrm{mg}$ every 24 hours, averaged dose is $40 \mathrm{mg}$ every 12 hours, whereas therapeutic dose, adjusted to the body weight is $I \mathrm{mg} / \mathrm{l} \mathrm{kg}$ of body weight every 12 hours. In pregnant women with one event of idiopathic VTE, who do not use chronic anticoagulant treatment, the following prophylaxis is suggested: Prophylactic dose of LMWH, low dose of HNF (5000 IU every I 2 hours), or administration of vitamin $\mathrm{K}$ antagonist as the bridge therapy with HNF or LMWH for the minimum period of 6 weeks post birth until INR 2.0 is obtained. For women with a VTE event and confirmed thrombophilia, who do not use anticoagulant therapy the following is suggested: Prophylactic or average dose of LMWH, low or average dose of HNF, or administration of vitamin $\mathrm{K}$ antagonist as the bridge therapy with HNF or LMWH for the minimum period of 6 weeks post birth until INR 2.0 is obtained. In women who have had at least two VTE events or are using chronic anticoagulant therapy, it is suggested that post-birth, LMWH or HNF at an adjusted dose is administered and chronic treatment with an oral anticoagulant is restored. At the same time, in all women who have had DVT, it is suggested to use pressure class II elastic stockings. Standard measures for the prevention of relapses include administration of oral anticoagulants: warfarin and acenocoumarol. Consideration of therapy using LMWH is valid in the situation where therapeutic values of the INR index are difficult to obtain, VTE relapse occurs during treatment with an oral anticoagulant, in pregnant individuals with hepatic impairment, in case of alcohol abuse, and in cases which are potentially qualified for a surgical procedure. The period of therapy application should be individualized and it should last for a minimum period of 3 months or it should constitute unlimited therapy if it is a subsequent VTE event [27]. Administration of vitamin K antagonists in the second and third trimester of gestation is associated with greater risk for abnormalities within the central nervous system and internal organs of the fetus, known as fetopathy or warfarin embryopathy [28]. Vitale et al. [29] determined that in pregnant women with a mechanical heart valve, the prevalence of this complication depends on the daily dose of warfarin. It is presently believed that the use of vitamin K antagonists during gestation exposes the child to an elevated risk of malformations, and their use shall be restricted to where it is absolutely necessary. Considering the fact that vitamin $\mathrm{K}$ antagonists do not penetrate milk, their usage during breastfeeding is safe [30].

In patients with cancer, the risk of VTE is 4- to 6-fold greater than in the general population [3I]. The greatest risk of VTE concerns malignant tumours of the pancreas, brain, ovary, stomach, lungs, kidneys, multiple myeloma, non-Hodgkin lymphomas, and Hodgkin lymphomas [32]. The risk of VTE is also high during the first months of neoplasm diagnosis and it may last for many years. Also, the risk of VTE increases several-fold during chemotherapy [33]. Antithrombotic drugs used in prophylaxis and treatment of VTE patients with cancer include LMWH (which are drugs of choice), HNF, fondaparinux (in prophylaxis), vitamin $\mathrm{K}$ antagonist with frequent INR control. (according to current knowledge this is no longer current) If previously, a patient has used one of the DOAC due to other indications and a VTE event occurred, then LMWH is the drug of choice, since the incident suggests unsuccessful anticoagulation [34]. 
Considering certain restrictions of DOAC use in patients with damaged liver and coagulation disorders, with weight in excess of $120 \mathrm{~kg}$, with antiphospholipid syndrome, using prasugrel and ticagrelor or drugs interacting with DOAC (influencing glycoprotein $\mathrm{P}$ and CYP3A4 cytochrome enzymes, antiplatelet agents clopidogrel, ASA, and NSAID), the possibility of LMWH therapy should also be taken into account [35].

The use of $\mathrm{LMWH}$ is also recommended for patients with visceral vein thrombosis associated with cancer (20-27\% of patients) and in persons with high risk of bleeding (cirrhosis, esophagus varices) [36]. Vein thrombosis with an atypical location is the cerebral vein thrombosis (CVT). It typically occurs in young women burdened with risk factors (head traumas, ENT and neurosurgical treatments, lumbar punctures, oral contraception). During the first days after a diagnosis of CVT, LMWH or HNF should be used, followed by a possible transition to VKA, if the patient's condition stabilizes [35].

Following the recommendations of the American College of Chest Physicians (ACCP), in patients with high risk of thromboembolic complications, the recommended procedure is the use of bridge anticoagulation therapy in the perioperative period instead of anticoagulant treatment cessation [37]. The REGIMEN register comparing the efficiency of bridge therapy of $\mathrm{HNF}$ and LMWH in a population of 901 patients demonstrated that in the group of patients using LMWH, these complications were observed only in $0.9 \%$ versus $2.4 \%$ in the group treated with HNF, while serious bleeding occurred in $5.5 \%$ versus $3.3 \%$ of treated patients, respectively [38].

The ACCP guidelines of 2016, which concern VTE prophylaxis and treatment [39], recommend that the preferred drugs in the first 3 months of treatment of patients without cancer are DOAC drugs - apixaban, rivaroxaban, edoxaban, and dabigatran. Considering the treatment scheme for two of the aforementioned drugs, i.e., edoxaban and dabigatran, LMWH can also be used for the first 5-10 days of treatment, in the preliminary phase.

The minimum period of treatment of the first VTE event is 3 months. This time is prolonged in patients after the first event of massive, unprovoked, proximal DVT or PE with a low or moderate risk of bleeding complications [39]. Chronic treatment is also used for patients with concomitant cancer and stable relapse risk factors. Another indication for relapse is thrombosis associated with the presence of a catheter. Perpetual antithrombotic treatment should be considered after the first event of unprovoked proximal DVT and/or PE in the group with a low or moderate risk of bleeding complications and following two events of unprovoked
VTE. One of the possible forms of therapy in the chronic treatment of VTE is LMWH used in monotherapy for 6 months in the course of cancer. It is recommended to use the full therapeutic dose for the first month, followed by $75 \%$ of the therapeutic dose. Another indication of chronic treatment is VTE treatment in pregnant women [35].

Both in prophylaxis as well as in VTE treatment, LMWHs are still widely used despite the introduction of DOAC-type drugs in the market. The numerous randomization studies on this type of drugs are typically non-inferiority tests designed to indicate equal or not less efficacy of newly introduced drugs in comparison to LMWH, most frequently, enoxaparin. Further research is needed to assess the efficacy and safety of their use and the time of therapy, which will enable the assessment of individual drugs in small patient groups treated for VTE. At present, enoxaparin - most frequently used with $\mathrm{LMWH}$, characterized by a large number of clinical studies - remains an efficient alternative in various clinical aspects of VTE treatment.

\section{Conflict of interest}

None.

\section{References:}

I. Praca zbiorowa. Polskie Wytyczne Profilaktyki i Leczenia Żylnej Choroby Zakrzepowo-Zatorowej. Medycyna Praktyczna. Wyd. specjalne. 2012.

2. Robertson L, Kesteven P, McCaslin JE, et al. Oral direct thrombin inhibitors or oral factor $\mathrm{Xa}$ inhibitors for the treatment of deep vein thrombosis. Cochrane Database Syst Rev. 2015(6): CD010956, doi: 10.1002/1465/858.CD010956.pub2, indexed in Pubmed: 26123214.

3. Huerta $C$, Johansson S, Wallander MA, et al. Risk factors and short-term mortality of venous thromboembolism diagnosed in the primary care setting in the United Kingdom. Arch Intern Med. 2007; 167(9): 935-943, doi: 10.1001/archinte.167.9.935, indexed in Pubmed: 17502535.

4. Heit JA, Mohr DN, Silverstein MD, et al. Predictors of recurrence after deep vein thrombosis and pulmonary embolism: a population-based cohort study. Arch Intern Med. 2000; 160(6): 76I-768, indexed in Pubmed: 10737275.

5. Prandoni P, Noventa F, Ghirarduzzi A, et al. The risk of recurrent venous thromboembolism after discontinuing anticoagulation in patients with acute proximal deep vein thrombosis or pulmonary embolism. A prospective cohort study in I,626 patients. Haematologica. 2007; 92(2): 199-205, indexed in Pubmed: 17296569.

6. Tagalakis V, Patenaude V, Kahn SR, et al. Incidence of and mortality from venous thromboembolism in a real-world population: the Q-VTE Study Cohort. Am J Med. 2013; 126(9): 832. el3-832.e2I, doi: 10.1016/j.amjmed.2013.02.024, indexed in Pubmed: 23830539.

7. Kearon C, Akl EA, Comerota AJ, et al. Antithrombotic therapy for VTE disease: antithrombotic therapy and prevention of thrombosis, 9 $^{\text {th }}$ ed: American College of Chest Physicians 
Evidence-Based Clinical Practice Guidelines. Chest. 2012; 141 (2 Suppl): e4I9S-e496S, doi: $10.1378 /$ chest.1I-230I, indexed in Pubmed: 22315268.

8. Wells PS, Anderson DR, Rodger M, et al. Evaluation of D-dimer in the diagnosis of suspected deep-vein thrombosis. $\mathrm{N}$ Engl J Med. 2003; 349(13): 1227-1235, doi: 10.1056/NEJMoa023।53, indexed in Pubmed: 14507948.

9. Bates SM, Jaeschke R, Stevens SM, et al. Diagnosis of DVT: antithrombotic therapy and prevention of thrombosis, 9th ed: american college of chest physicians evidence-based clinical practice guidelines. Chest. 2012; 14 I (2 Suppl): e35IS-e4I8S, doi: 10.1378/chest. I I-2299, indexed in Pubmed: 22315267.

10. Barbar S, Noventa F, Rossetto V, et al. A risk assessment model for the identification of hospitalized medical patients at risk for venous thromboembolism: the Padua Prediction Score. J Thromb Haemost. 2010; 8(I I): 2450-2457, doi: 10.1 I I I/j. I5387836.2010.04044.x, indexed in Pubmed: 20738765.

II. van der Hulle T, Cheung WY, Kooij S, et al. YEARS study group. Simplified diagnostic management of suspected pulmonary embolism (the YEARS study): a prospective, multicentre, cohort study. Lancet. 2017; 390(10091): 289-297, doi: 10.1016/S01406736(I7)30885-I, indexed in Pubmed: 28549662.

12. Zawilska K, Jaeschke R, Tomkowski W, et al. Polskie wytyczne profilaktyki i leczenia żylnej choroby zakrzepowo-zatorowej. Medycyna Praktyczna, Wyd. specjalne. 2009; I: I-55.

13. National Institute for Health and Care Excellence. CG92: Venous thromboembolism — reducing the risk. 2010. http://guidance.nice.org.uk/CG92 (I.05.20I4).

14. Weitz JI. New oral anticoagulants: a view from the laboratory. Am J Hematol. 2012; 87 Suppl I: SI33-SI36, doi: 10.1002/ ajh.23139, indexed in Pubmed: 22407747.

15. Hass B, Pooley J, Harrington AE, et al. Treatment of venous thromboembolism - effects of different therapeutic strategies on bleeding and recurrence rates and considerations for future anticoagulant management. Thromb J. 2012; 10(1): 24, doi: 10.1 186/1477-9560-10-24, indexed in Pubmed: 23276253.

16. Ageno W, Gallus AS, Wittkowsky A, et al. Oral anticoagulant therapy: Antithrombotic Therapy and Prevention of Thrombosis, 9th ed: American College of Chest Physicians Evidence-Based Clinical Practice Guidelines. Chest. 2012; 141 (2 Suppl): e44S-e88S, doi: 10.1378/chest. I I-2292, indexed in Pubmed: 22315269.

17. Charakterystyka produktu leczniczego Neoparin. http://www. urpl.gov.pl/pl.

18. Samama MM, Desnoyers PC. Low molecular weight heparins: an overview. Thrombosis, Scientic and Clinical Prospectives. 1995; 5: 95-106.

19. Lim W, Dentali F, Eikelboom JW, et al. Meta-analysis: low-molecular-weight heparin and bleeding in patients with severe renal insufficiency. Ann Intern Med. 2006; 144(9): 673-684, indexed in Pubmed: 16670137.

20. Szczeklik A. Choroby wewnętrzne. Kompendium medycyny praktycznej 2010. Wydanie II zaktualizowane i rozszerzone. Medycyna Praktyczna, Kraków 2010.

21. Qaseem A, Snow V, Barry P, et al. Joint American Academy of Family Physicians/American College of Physicians Panel on Deep Venous Thrombosis/Pulmonary Embolism, Joint American Academy of Family Physicians/American College of Physicians Panel on Deep Venous Thrombosis/Pulmonary Embolism. Cur- rent diagnosis of venous thromboembolism in primary care: a clinical practice guideline from the American Academy of Family Physicians and the American College of Physicians. Ann Fam Med. 2007; 5(I): 57-62, doi: 10.1370/afm.667, indexed in Pubmed: 17261865 .

22. Previtali E, Bucciarelli P, Passamonti SM, et al. Risk factors for venous and arterial thrombosis. Blood Transfus. 201 I; 9: 120-38.

23. Coppola R, Mari D, Lattuada A, et al. Von Willebrand factor in Italian centenarians. Haematologica. 2003; 88(I): 39-43, indexed in Pubmed: $|255| 825$.

24. Wilkerson WR, Sane DC. Aging and thrombosis. Semin Thromb Hemost. 2002; 28(6): 555-568, doi: 10.1055/s-2002-36700, indexed in Pubmed: 12536349.

25. Melis F, Vandenbrouke JP, Büller HR, et al. Estimates of risk of venous thrombosis during pregnancy and puerperium are not influenced by diagnostic suspicion and referral basis. Am J Obstet Gynecol. 2004; 191(3): 825-829, doi: 10.1016/j. ajog.2004.02.004, indexed in Pubmed: 15467549.

26. Cunningham FG, Leveno KL, Bloom SL. Thromboembolic disorders. In: Cunningham FG, Leveno KL, Bloom SL. ed. Williams obstetrics. McGraw \& Hill, New York 2005.

27. Sajdak S, Rybak Z, Oszkinis G. Wytyczne profilaktyki i leczenia żylnej choroby zakrzepowo-zatorowej w ciąży. Przeg. Gin. Poł. 2006; 6(4): 205-216.

28. McLintock C. Anticoagulant choices in pregnant women with mechanical heart valves: Balancing maternal and fetal risks - the difference the dose makes. Thrombosis Research. 2013; 131: S8-SI0, doi: 10.1016/50049-3848(13)70010-0.

29. Vitale N, De Feo M, De Santo LS, et al. Dose-dependent fetal complications of warfarin in pregnant women with mechanical heart valves. J Am Coll Cardiol. 1999; 33(6): 1637-1641, indexed in Pubmed: 10334435.

30. Trojnarska $\mathrm{O}$, Plaskota K. Leczenie przeciwkrzepliwe w czasie ciąży u kobiet $\mathrm{z}$ implantowanymi protezami zastawkowymi. Kardiol Pol. 2012; 70: 622-626.

31. Lyman GH, Khorana AA. Cancer, clots and consensus: new understanding of an old problem. J Clin Oncol. 2009; 27(29): 482 I-4826, doi: 10.1200/JCO.2009.22.3032, indexed in Pubmed: 19752337.

32. Lee A.Y. Thrombosis in cancer: an update on prevention, treatment, and survival benefits of anticoagulants. Hematology Am. Soc. Hematol. Educ. Program 2010: 144-149.

33. Chew HK, Wun T, Harvey D, et al. Incidence of venous thromboembolism and its effect on survival among patients with common cancers. Arch Intern Med. 2006; 166(4): 458-464, doi: 10.1001/archinte. 166.4.458, indexed in Pubmed: 16505267.

34. Wojtukiewicz M, Sierko E, Tomkowski W, et al. Wytyczne dotyczące profilaktyki i leczenia żylnej choroby zakrzepowo-zatorowej u chorych na nowotwory poddawanych leczeniu zachowawczemu. Onkologia w praktyce klinicznej - edukacja. 2006; 2: 73-101.

35. Zawilska K, Zawilska K. Praktyczne aspekty leczenia żylnej choroby zakrzepowo-zatorowej. Hematologia. 2017; 7(3): 23I-242, doi: 10.5603/hem.2016.0018.

36. Ageno W, Beyer-Westendorf J, Garcia DA, et al. Guidance for the management of venous thrombosis in unusual sites. J Thromb Thrombolysis. 2016; 4I(I): 129-143, doi: 10.1007/ s| |239-0|5-1308-I, indexed in Pubmed: 26780742. 
37. Douketis JD, Spyropoulos AC, Spencer FA, et al. Perioperative management of antithrombotic therapy: Antithrombotic Therapy and Prevention of Thrombosis, 9th ed: American College of Chest Physicians Evidence-Based Clinical Practice Guidelines. Chest. 2012; I4I(2 Suppl): e326S-e350S, doi: 10.1378/ chest. I I-2298, indexed in Pubmed: 223 I5266.

38. Spyropoulos AC, Turpie AGG, Dunn AS, et al. REGIMEN Investigators. Clinical outcomes with unfractionated heparin or low-molecular-weight heparin as bridging therapy in patients on long-term oral anticoagulants: the REGIMEN registry. J Thromb Haemost. 2006; 4(6): 1246-1252, doi: 10.1 I I I/j. I5387836.2006.01908.x, indexed in Pubmed: 16706967.

39. Kearon C, Akl EA, Ornelas J, et al. Antithrombotic Therapy for VTE Disease: CHEST Guideline and Expert Panel Report. Chest. 2016; 149(2): 315-352, doi: 10.1016/j.chest.2015.11.026, indexed in Pubmed: 26867832. 